\title{
REVIEW
}

\section{Current advances in orthodontic pain}

\author{
Hu Long, Yan Wang, Fan Jian, Li-Na Liao, Xin Yang and Wen-Li Lai
}

Orthodontic pain is an inflammatory pain that is initiated by orthodontic force-induced vascular occlusion followed by a cascade of inflammatory responses, including vascular changes, the recruitment of inflammatory and immune cells, and the release of neurogenic and pro-inflammatory mediators. Ultimately, endogenous analgesic mechanisms check the inflammatory response and the sensation of pain subsides. The orthodontic pain signal, once received by periodontal sensory endings, reaches the sensory cortex for pain perception through three-order neurons: the trigeminal neuron at the trigeminal ganglia, the trigeminal nucleus caudalis at the medulla oblongata and the ventroposterior nucleus at the thalamus. Many brain areas participate in the emotion, cognition and memory of orthodontic pain, including the insular cortex, amygdala, hippocampus, locus coeruleus and hypothalamus. A built-in analgesic neural pathway-periaqueductal grey and dorsal raphe-has an important role in alleviating orthodontic pain. Currently, several treatment modalities have been applied for the relief of orthodontic pain, including pharmacological, mechanical and behavioural approaches and low-level laser therapy. The effectiveness of nonsteroidal antiinflammatory drugs for pain relief has been validated, but its effects on tooth movement are controversial. However, more studies are needed to verify the effectiveness of other modalities. Furthermore, gene therapy is a novel, viable and promising modality for alleviating orthodontic pain in the future.

International Journal of Oral Science (2016) 8, 67-75; doi:10.1038/ijos.2016.24; published online 24 June 2016

Keywords: facial pain; gene therapy; inflammation; neural pathways; trigeminal ganglion

\section{INTRODUCTION}

Pain is defined as an unpleasant sensory and emotional experience associated with actual or potential tissue damage or is described in terms of such damage. With no exception, orthodontic pain is perceived as discomfort, dull pain and hypersensitivity in affected teeth. ${ }^{1-2}$ In most circumstances, pain motivates individuals to withdraw from damaging situations. However, because human beings are well acquainted with the fact that orthodontic pain is a normal adverse effect of tooth movement, orthodontic pain is well accepted by most orthodontic patients. Orthodontic pain is commonly referred to as tooth discomfort induced by orthodontic tooth movement, whereas a broader definition of orthodontic pain refers to any painful sensation, for example, mucosal ulcer, tongue discomfort and gingival lesion, caused by orthodontic appliances. ${ }^{3-4}$ The former and narrower definition of orthodontic pain is used in this review, unless indicated otherwise. In this review, we aimed to provide a current understanding of orthodontic pain, such as its characteristics, mechanisms, neural circuits and clinical management.

\section{CHARACTERISTICS OF ORTHODONTIC PAIN}

Orthodontic pain, defined as orofacial pain induced by orthodontic tooth movement, is commonly encountered in daily orthodontic practice. ${ }^{5-6}$ Orthodontic pain, with a prevalence of $72 \%-100 \%,{ }^{1-2,5}$ is perceived as soreness, pressure and tension in the affected teeth.
Orthodontic force, once exerted on teeth, initially activates sensory receptors in periodontal tissues and results in a cascade of nociceptive pain processing and transduction in both the peripheral and central nervous systems that is ultimately perceived by orthodontic patients. Orthodontic pain can be perceived during almost all treatment procedures: separator placement, initial wire engagement, banding, wearing elastics, rapid maxillary expansion and debonding. ${ }^{7-11}$ It has been well documented that orthodontic pain begins $12 \mathrm{~h}$ after applying orthodontic force, peaks after 1 day, gradually diminishes 3-7 days thereafter and returns to baseline levels after 1 month. ${ }^{12-14}$ Although orthodontic pain subsides in most patients 1 week following orthodontic treatments, $>40 \%$ of adolescent patients reported orthodontic pain after 1 week, indicating the potential long duration of orthodontic pain. ${ }^{15}$ Moreover, orthodontic pain is more than a painful sensation for patients, it decreases patients' health-related quality of life $\mathrm{e}^{16}$ and interferes with patients' masticatory performance and speech. Animal studies have indicated that orthodontic pain results in emotional stress ${ }^{17}$ and transient learning and memory deficits. $^{18}$

\section{MECHANISMS OF ORTHODONTIC PAIN}

Once orthodontic forces are applied on teeth, marked responses occur at paradental tissues, including periodontal tissues and the dental pulp. ${ }^{19-21}$ A cascade of self-limiting inflammatory reactions, including 
cellular, vascular, neural and immunological reactions, act in an orchestrated way to ultimately result in orthodontic pain and tooth movement. In effect, orthodontic pain and orthodontic tooth movement are two interrelated and dependent biological events with local inflammation being their common mechanism. The products of local inflammation (for example, prostaglandin and bradykinin) act on sensory endings to incite painful sensations. ${ }^{22-24}$ Therefore, the mechanisms underlying orthodontic pain lie in periodontal inflammatory responses induced by orthodontic forces. The periodontal inflammation response includes three components: vascular, cellular and chemical events. The three components interact with each other and form a network. For clarity, these three components will be discussed separately in this review, but, to recapitulate, they are intrinsically intercorrelated. The mechanisms of orthodontic pain are illustrated in Figure 1.

\section{Vascular events}

Optimal orthodontic force, coined by Schwarz in 1932, was defined as the force $\left(20-25 \mathrm{~g} \cdot \mathrm{cm}^{-2}\right)$ leading to a change in tissue pressure that approximated the capillary blood pressure in the compressed periodontal tissues. ${ }^{25}$ Thus, when optimal forces are applied on teeth, the vascular vessels at the compressed sites are squeezed and local ischaemia ensues. ${ }^{26}$ The local ischaemia incites an increased anaerobic respiration in periodontal cells (for example, fibroblasts) and a subsequent acidosis. The resulting local acidic signals are transduced to painful signals by a cardinal molecule: acid-sensing ion channel 3 (ASIC3). ASIC3, an ion channel receptor described for $\mathrm{H}^{+}$, has been well documented to be expressed on periodontal sensory endings. ${ }^{27}$ Once a periodontal acidic microenvironment occurs following the application of orthodontic forces, abundant local $\mathrm{H}^{+}$binds to ASIC3 on periodontal sensory endings and elicits painful sensations. ${ }^{28}$ Moreover, a dual role of ASIC3 in orthodontic pain may exist. It has been reported that ASIC3 is expressed in mechanoreceptors (Ruffini body) within periodontal tissues, imparting its role in mechanosensation for orthodontic forces. ${ }^{27}$ However, given that orthodontic force is mild in nature, the contribution of orthodontic force mechanosensation to pain has been neglected. This mechanism could explain the phenomenon that orthodontic patients feel no pain or just mild pain within the early hours following orthodontic force application, ${ }^{12-14}$ given that orthodontic force-induced local inflammation occurs $\sim 12 \mathrm{~h}$ later.

The painful sensation mediated by ASIC3, once transmitted to trigeminal neurons at the trigeminal ganglia, stimulate trigeminal neurons to release several neurogenic mediators both centrally (trigeminal nucleus) and peripherally (periodontal tissues), including but not limited to calcitonin gene-related peptide (CGRP) and

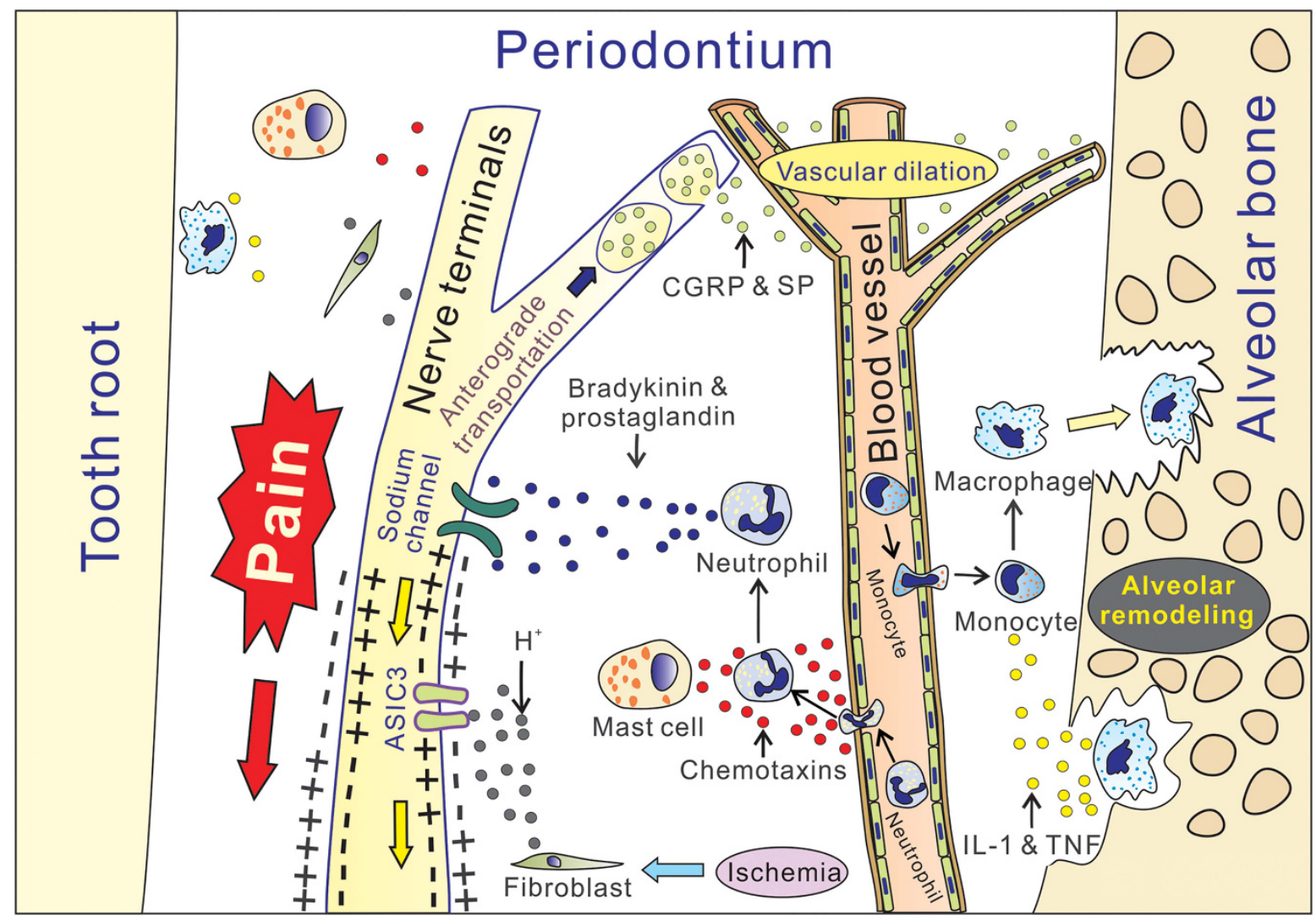

Figure 1 The mechanisms underlying orthodontic pain. The dental root (left) moves in the direction of force towards the alveolar bone (right) with the periodontium between them. Upon vascular compression and local ischaemia, periodontal cells, mainly fibroblasts, undergo anaerobic respiration and cause local acidosis. The proton ion $\left(\mathrm{H}^{+}\right)$binds to ASIC3 receptors on sensory endings to generate pain. As local ischaemia progresses, mast cells and fibroblasts release various chemotaxins to recruit leucocytes, for example, neutrophils and monocytes. These leucocytes release abundant inflammatory mediators (for example, bradykinin and prostaglandin) and cytokines (for example, IL-1 and TNF). Bradykinin and prostaglandin bind to sensory endings to generate painful sensations. The released cytokines amplify local inflammation and stimulate monocyte-derived macrophages to participate in alveolar bone remodelling. Moreover, via anterograde transportation, sensory endings release various neurogenic mediators (for example, CGRP and SP) to dilate local blood vessels and enhance local inflammation, amplifying local painful sensation and alveolar remodelling. CGRP, calcitonin gene-related peptide; IL, interleukin; SP, substance P; TNF, tumour necrosis factor. 
substance P (SP). ${ }^{19-20,29-30}$ These released neurogenic mediators cause local vascular dilation and augment local inflammation, ${ }^{31}$ which in turn promote trigeminal sensory endings to release CGRP, thereby amplifying orthodontic pain in a positive-feedback loop. ${ }^{30}$ It is noteworthy that these neurogenic mediators have been reported to stimulate the production of prostaglandins, ${ }^{32}$ which could enhance orthodontic pain because prostaglandins could generate painful sensations upon binding to sensory endings. ${ }^{33}$

Moreover, this ischaemic and acidic microenvironment ignites periodontal endothelial cells and fibroblasts to release nitric oxide (NO). This signalling molecule increases periodontal vascular permeability. ${ }^{34-35}$ Once periodontal vascular permeability increases, abundant leucocytes, including neutrophils, monocytes and lymphocytes, are recruited to periodontal tissues. ${ }^{36-40}$ Upon activation at periodontal tissues, these cells release various chemokines, cytokines and inflammatory mediators that further amplify local inflammation and cause a painful sensation. ${ }^{33,41}$

\section{Cellular events}

Once local inflammation occurs, vascular permeability increases and numerous leucocytes, including neutrophils, mast cells, macrophages, $\mathrm{T}$ cells and monocytes, are recruited and infiltrate periodontal tissues. ${ }^{36-40}$ In response to local inflammation, periodontal mast cells and macrophages release various mediators that facilitate leucocyte recruitment to periodontal tissues. ${ }^{42}$ Among these mediators, histamine and tumour necrosis factor-alpha (TNF- $\alpha$ ) released from mast cells stimulate adhesion protein upregulation in vascular endothelial cells. ${ }^{43}$ In turn, these upregulated adhesion proteins on endothelial cells facilitate leucocyte adhesion and transmigration through vascular vessels. Moreover, following extravasation from the blood, leucocytes migrate towards periodontal sites. This process is mediated by chemotaxins. In particular, neutrophil chemotaxis to periodontal tissues is primarily dependent on mast cell-derived CXCL2. ${ }^{44-45}$ By contrast, different types of leucocytes use different molecules for chemotaxis, for example, recruitment of monocytes is governed by monocyte chemotactic protein 1 , which is upregulated in response to orthodontic forces. ${ }^{36}$ Recent research has indicated that two types of macrophages are differentiated from monocytes in inflammatory conditions: M1 and M2 macrophages. ${ }^{46}$ The M1 macrophage promotes phagocytosis and cell damage, whereas the M2 macrophage facilitates cell proliferation and healing, ${ }^{47-48}$ suggesting that a balance between M1 and M2 determines tissue damage and healing. A recent study revealed that M1 macrophages promote alveolar bone resorption following the application of orthodontic force, ${ }^{37}$ suggesting that M1 macrophages are important pro-inflammatory cells in orthodontic pain. However, the role of M2 macrophages or M1/M2 macrophage balance in orthodontic pain merits further investigation.

\section{Chemical events}

As mentioned above, various leucocytes and inflammatory cells are recruited and activated in periodontal tissues. These cells release abundant inflammatory mediators, chemokines and cytokines within periodontal tissues, including but not limited to IL-1, IL-6, prostaglandin, TNF- $\alpha$, interferon-gamma (IFN- $\gamma$ ), macrophage-colonystimulating factors (M-CSF) and vascular endothelial growth factor (VEGF). ${ }^{33,41,49-51}$ These mediators act in concert to incite and amplify local inflammation in the early stages of orthodontic pain. IL-1, IL-6, TNF- $\alpha$, IFN- $\gamma$ and M-CSF are active in stimulating osteoblasts and osteoclasts that participate in periodontal bone remodelling and subsequent tooth movement, ${ }^{52-55}$ which in turn augments local inflammation. Moreover, M-CSF stimulates the conversion of monocytes to macrophages and the recruitment and differentiation of osteoclasts, ${ }^{51}$ which enhance local inflammation and subsequent painful sensation. In particular, the locally released prostaglandin generates a painful sensation by binding to periodontal sensory endings. ${ }^{22}$

As orthodontic pain progresses, the body's built-in analgesic mechanisms are activated to alleviate pain and to prevent damage to periodontal tissues, which is the basic difference from periodontitis. These analgesic mechanisms are complex and still poorly understood. However, what is clear is that endogenous opioid or opioid-like molecules and neural pathways may participate in these analgesic processes, ${ }^{56}$ which will be explained in detail in the next section of this review. At this stage, the painful sensation subsides and the aforementioned VEGF promotes local neovascularizaion and bone remodelling. At the next appointment, when orthodontic forces are re-applied, this cycle re-occurs.

\section{NEURAL CIRCUITS AND REGULATION OF ORTHODONTIC PAIN} Orthodontic pain transmission pathways

The neural circuits for the transmission of orthodontic pain are illustrated in Figure 2. Orthodontic tooth movement, once applied on teeth, is received by periodontal sensory endings as nociceptive stimuli. The nociceptive stimuli are transmitted ultimately to somatosensory cortex via three-order neurons. The first-order neurons are trigeminal neurons that are located at the trigeminal ganglia. Trigeminal neurons, being pseudounipolar neurons, possess both peripheral and central processes. Their peripheral processes run peripherally to facial skin, periodontal tissue and oral mucosa, and form sensory endings that receive nociceptive, mechanical and thermal sensations. Moreover, their central processes project centrally to synapse with the secondorder neurons, the trigeminal nucleus caudalis, which are located in the medullar oblongata. Trigeminal nucleus caudalis is a nucleus that extends almost the whole medulla cephalocaudally. Then, after entering the medulla, the axons in the central processes of the trigeminal neurons travel caudally to synapse with the trigeminal nucleus. In turn, the trigeminal nucleus send fibres to form the trigeminothalamic tract that decussates to the contralateral side and ascends to make synapses with the ventroposterior nucleus of the thalamus. Subsequently, the thalamus sends fibres to many areas of the brain, including the hippocampus, amygdala, insular cortex and somatosensory cortex, and these brain areas project fibres to converge and integrate orthodontic pain information at the sensory cortex. Finally, orthodontic patients perceive orthodontic pain and generate their emotions (for example, anxiety and unpleasant feelings) and memory towards orthodontic pain. The trigeminal nucleus at the medulla oblongata sends fibres to activate the facial nucleus and the activated facial nucleus in turn innervate facial muscles via the facial nerve to produce facial grimacing and eye closure..$^{57}$ This mechanism is generated as a revolution for animal sociality because its aim is to nonverbally express pain and to alert companions. ${ }^{58-59}$ This mechanism could explain facial grimacing and eye closure that occurs in some orthodontic patients when undergoing power chain mounting or wire engaging procedures. Moreover, this mechanism provides justification for assessing pain levels through facial expressions in animal models of orthodontic pain. ${ }^{60}$

Among the three-order neurons that regulate orthodontic pain, the trigeminal neurons at the trigeminal ganglia are by far the most studied. Following orthodontic pain, numerous molecules are upregulated in the trigeminal ganglia, for example, P2X3 and CGRP. ${ }^{61-64}$ These molecules change the biological characteristics of trigeminal neurons, for example, increased excitability. ${ }^{65}$ With increased 


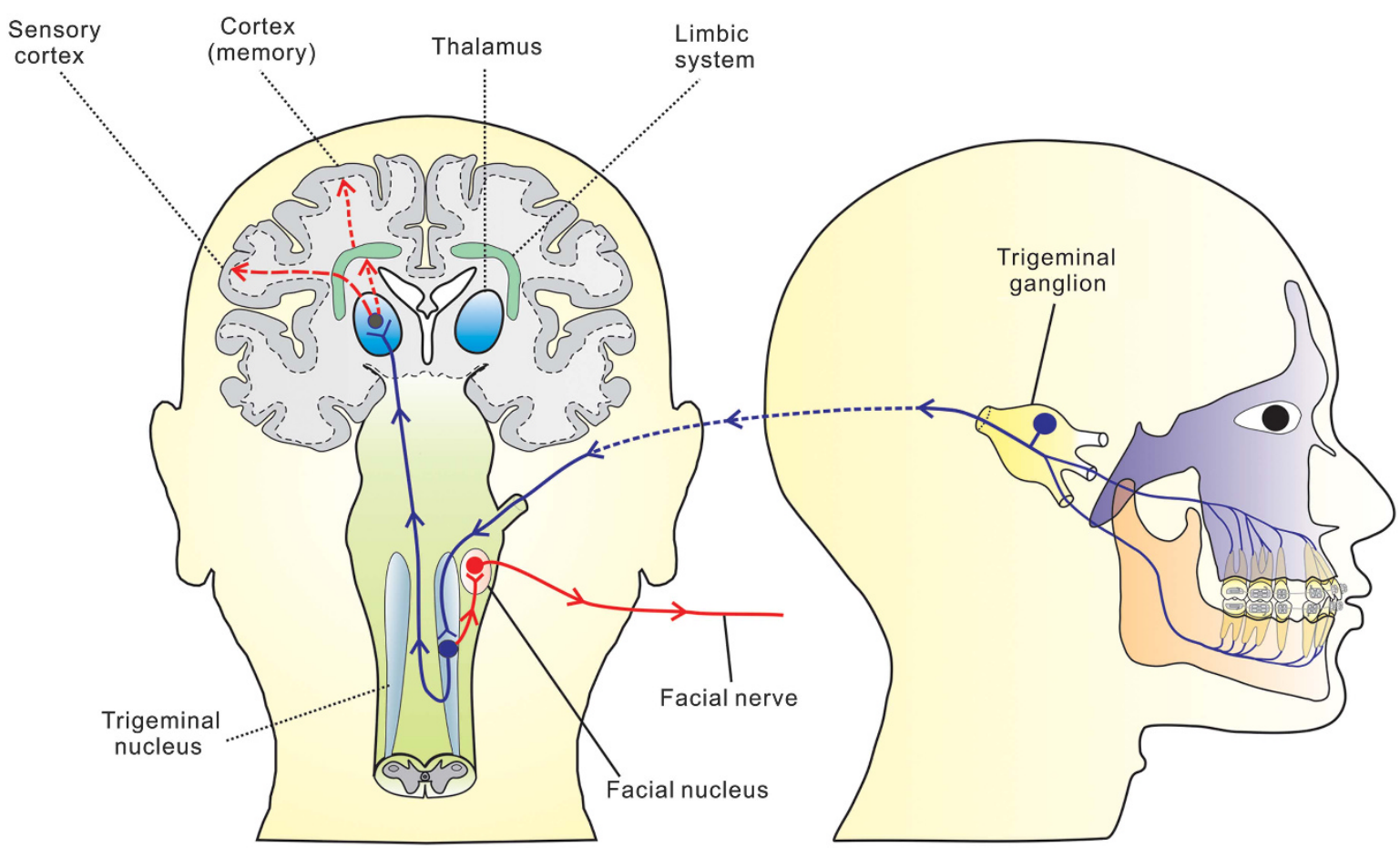

Figure 2 Pain transmission pathways for orthodontic pain.

excitability, trigeminal neurons are more readily stimulated, resulting in thermal and mechanical hyperalgaesia. ${ }^{66-67}$ This mechanism could explain the phenomenon that a gentle bite causes pain in orthodontic patients suffering from orthodontic pain. The mechanisms underlying sensitization of trigeminal neurons could be better explained by the interactions between trigeminal neurons and satellite glial cells. In the trigeminal ganglia, satellite glial cells $(90 \%)$ outnumber neurons (10\%). Abundant satellite glial cells wrap one neuron to form a functional unit with gap junctions and paracrine communications. ${ }^{68-70}$ Our studies (not yet published) and those published elsewhere have consistently revealed that CGRP is upregulated in trigeminal neurons following tooth movement. ${ }^{64}$ The resulting upregulated CGRP is released from trigeminal neurons and sensitises their surrounding satellite glial cells..$^{7-72}$ Upon sensitization, the satellite glial cells release $\mathrm{NO}$, and released NO in turn enhances CGRP synthesis in trigeminal neurons, ${ }^{73}$ rendering this process a positive-feedback loop. The upregulated CGRP, on the one hand, increases the excitability of trigeminal neurons and, on the other hand, is anterograde-transported to periodontal tissues, resulting in amplification of orthodontic pain. ${ }^{30}$ Orthodontic pain is regulated through the interactions between trigeminal neurons and satellite glial cells at the level of the trigeminal ganglia. However, more research of second- or third-order neurons is encouraged to unravel the exact regulatory mechanisms for orthodontic pain.

\section{Emotion and cognition of orthodontic pain}

As presented in Figure 3, the insular cortex, located within the lateral sulcus, harbours reciprocal connections with the thalamus, limbic system and cerebral cortices, and has an important role in pain perception, emotion and cognition. ${ }^{74}$ Subjective pain experiences are generated by the integration of afferent pain signals with the available personal cognitive state $^{75}$ which could explain that individual perceptions of orthodontic pain differ greatly in clinical practice. $^{76-77}$ A seminal study revealed that the insular cortex may be importantly involved in the integration of pain information with previous cognitive information, ${ }^{75}$ probably through reciprocal connections between the insular cortex and the cerebral cortex. The role of the insular cortex in the integration of orthodontic pain is further supported by our previous functional magnetic resonance imaging (MRI) study, wherein the insular cortex was revealed to be activated among orthodontic patients following separator placement. ${ }^{78}$ When patients were in positive cognitive states (for example, distracted from pain and taking a placebo), through interactions between the insular cortex and cerebral cortex, the activity of the insular cortex could be reduced and pain relieved, ${ }^{79-80}$ which explains the analgaesic mechanisms of attention distraction and placebo effect on pain. Similarly, in our clinical practice, we could apply attention distraction and placebo to relieve orthodontic pain, which was partially supported by our previous study in which cognitive behavioural treatment (CBT) was found to alleviate orthodontic pain, ${ }^{81}$ and by a study reported elsewhere in which high physical activity (distraction from pain) relieved orthodontic pain..$^{82}$

A large body of evidence indicates that orthodontic pain can generate negative emotions (for example, anxiety) among orthodontic patients. ${ }^{83-86}$ Moreover, negative emotions would in turn exacerbate orthodontic pain among orthodontic patients. ${ }^{87-88}$ Thus, orthodontic pain and negative emotions are intertwined, and this connection could be explained by the role of limbic system. As is well documented, the limbic system, located at the medial rim of the brain, consists of several structures (for example, the hippocampus and amygdala) with complex and looped connections that participate in emotion and memory. ${ }^{89}$ As mentioned above, the ventroposterior nucleus of the thalamus relays orthodontic pain signals to the cortex. In turn, the orthodontic pain signal at the thalamus is sent to the amygdala; this process was confirmed by a study in which orthodontic tooth movement activated the amygdala. ${ }^{90}$ Then, the amygdala processes 
(stress, memory, emotion \& cognition related to orthodontic pain)

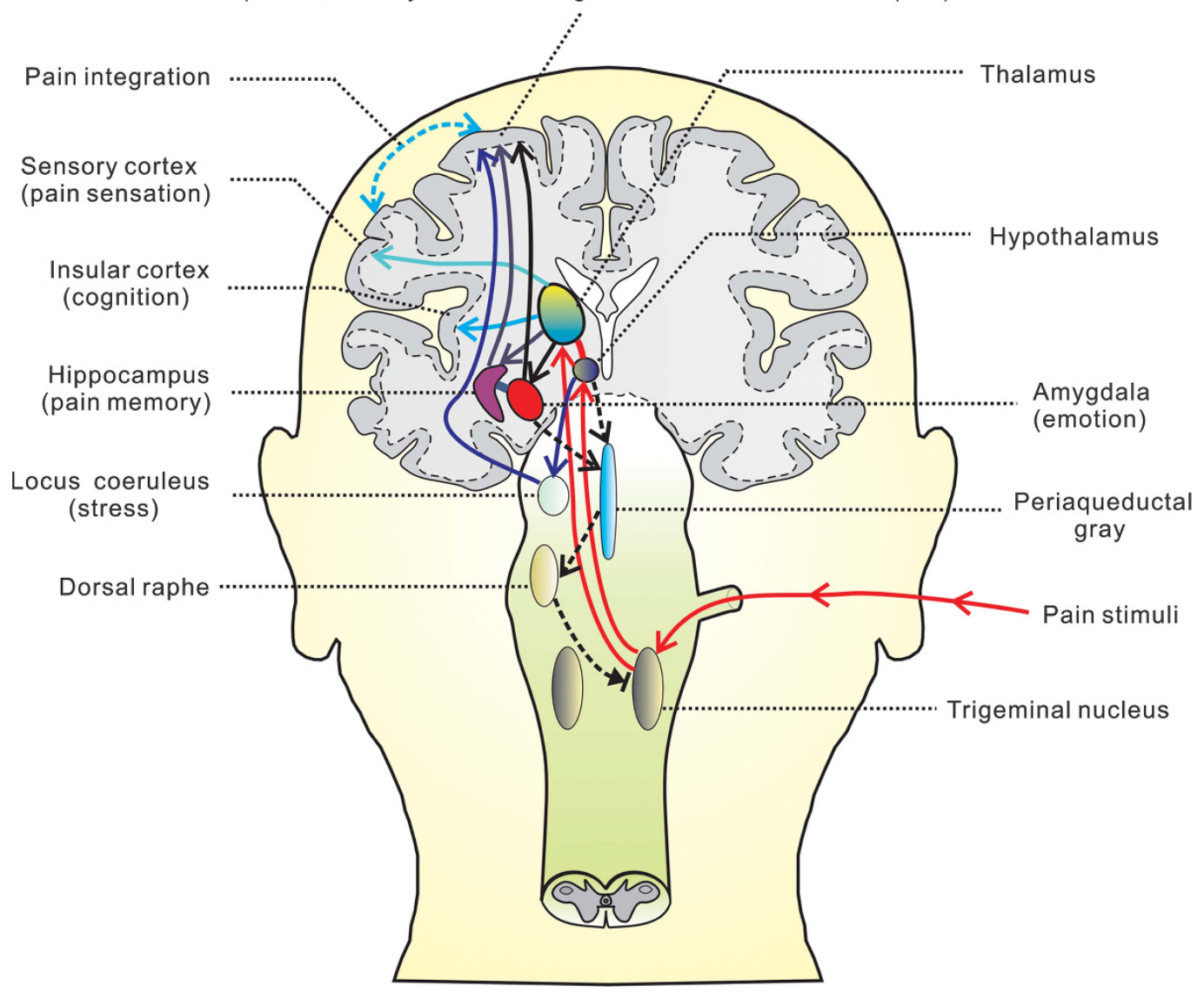

Figure 3 Neural circuits of orthodontic pain.

the pain signals and sends its processed information to the cortex where pain is perceived and anxiety is generated. In turn, the information about anxiety is transmitted from the cortex to the amygdala and then to a regulatory descending system (periaqueductal grey-dorsal raphe) that ultimately influences the trigeminal nucleus and subsequent pain sensations. ${ }^{91}$

A seminal study found that previous pain experience could influence the perception of orthodontic pain. ${ }^{15}$ Moreover, it has been revealed that the sensitivity of the trigeminal nerve is higher in patients who had previous orthodontic pain. ${ }^{92}$ These results indicate that memory of orthodontic pain alters pain perception among orthodontic patients. The effect of pain memory on pain perception could be explained by the role of hippocampus. ${ }^{93-96}$ Once orthodontic pain is perceived at the level of the cortex, the cortex searches for pain memory and, if it exists, pain memory information is sent to limbic system for processing. The processed pain memory information is returned to the cortex where present pain information and pain memory information are integrated, thereby altering current pain perception. An animal study found that orthodontic pain could impair memory and learning through inducing hippocampal neuron apoptosis. ${ }^{18,97}$ This finding was reinforced by another study in which chronic pain was revealed to interfere with memory formation in the hippocampus. ${ }^{98}$ This effect of pain on the hippocampus may be a built-in strategy to alleviate chronic pain, but the effect on orthodontic pain in humans need to be validated in future studies.
Several animal studies have revealed that orthodontic pain could cause stress, ${ }^{17,99}$ which could be explained by the role of the locus coeruleus given that orthodontic pain activates the locus coeruleus. ${ }^{100}$ The locus coeruleus, the major noradrenergic nucleus of the brain, projects fibres to extensive areas throughout the neuraxis and has an essential role in the regulation of arousal and autonomic activity. ${ }^{101}$ Once orthodontic pain signals arrive at the trigeminal nucleus, the information about orthodontic pain is transmitted through the trigeminohypothalamic tract to the hypothalamus, ${ }^{102}$ which relays this information to the locus coeruleus. Once activated, the locus coeruleus activates the sympathetic system and causes stress. ${ }^{101}$ Moreover, the activated locus coeruleus results in the enhancement of alertness and arousal, ${ }^{103}$ which could partially explain the phenomenon that some orthodontic patients wake up in the deep night due to high levels of orthodontic pain.

\section{Analgesic neural circuits for orthodontic pain}

Orthodontic pain, as mentioned above, peaks on the 1st day and gradually wanes through the 5th day following orthodontic tooth movement. ${ }^{12-14}$ The high pain levels at the initial stages of each episode of orthodontic treatment are aimed to alert humans about the nociceptive stimuli. However, the pain levels decrease gradually afterwards, indicating that an intrinsic built-in analgesic mechanism dominates the late stages of each episode of orthodontic treatment. Humans possess many intrinsic analgesic mechanisms that could be activated in response to pain. Endogenous opioid, in particular, is the 
most extensively studied mechanism. ${ }^{104}$ In response to orthodontic pain, endogenous opioid and opioid receptors are upregulated in the trigeminal nucleus, ${ }^{56,105}$ which act in concert to exert an intrinsic analgesic effect on orthodontic pain. However, in this review, we will focus on a neural circuit that exerts pain modulation: the periaqueductal grey—dorsal raphe—trigeminal nucleus. ${ }^{91}$ The periaqueductal grey, the grey matter located around the cerebral aqueduct in the tegmentum of the midbrain, is a major component of the descending pain inhibitory system. ${ }^{106}$ The periaqueductal grey contains endogenous opioid-releasing neurons that may contribute to its analgesic function. ${ }^{107}$ The dorsal raphe, located at the midline of the brainstem, is a part of the raphe nucleus and has an important role in pain modulation. ${ }^{108}$ As presented in Figure 3, the trigeminothalamic tract that carries the fibres from the trigeminal nucleus to the thalamus has connections with the periaqueductal grey and dorsal raphe. Once orthodontic pain occurs, the periaqueductal grey and dorsal raphe is activated. ${ }^{100}$ The activated periaqueductal grey receives fibres from the amygdala and brain cortex, which tailor the activity of the periaqueductal grey so that it sends analgesic signals only at late stages of each episode of orthodontic treatment. ${ }^{91}$ Once the periaqueductal grey is permitted by the amygdala and the cortex to send signals, it activates the dorsal raphe, and the activated dorsal raphe in turn regulates the activity of the trigeminal nucleus, ${ }^{109-110}$ thereby relieving orthodontic pain. ${ }^{91}$ Furthermore, it has been reported that the periaqueductal grey could be activated by listening to music, ${ }^{111}$ which could explain the phenomenon that listening to music alleviates orthodontic pain. ${ }^{112}$ However, the exact mechanisms by which listening to music activates the periaqueductal grey are poorly understood. The mechanisms are probably associated with the limbic system and the locus coeruleus, but the exact neural mechanisms merit further functional MRI studies.

\section{MANAGEMENT OF ORTHODONTIC PAIN}

Orthodontic pain is inevitably an adverse effect of orthodontic treatment. To date, numerous modalities have been invented to alleviate orthodontic pain in clinical practice, including pharmacological approaches, ${ }^{113-115}$ mechanical approaches, ${ }^{116-117}$ laser irradiation therapy ${ }^{68-69}$ and behavioural approaches. ${ }^{14,81}$ Furthermore, a novel modality for pain relief — gene therapy—is gaining popularity and may be promising in future pain relief among orthodontic patients.

\section{Pharmacological approach}

Nonsteroidal anti-inflammatory drugs (NSAIDs) have been used for the relief of orthodontic pain for decades. Their effectiveness in orthodontic pain relief has been validated, but their by-productreducing the rate of tooth movement-is still being debated, ${ }^{118-120}$ making NSAIDs not routinely applied for pain control in orthodontic practice. $^{121}$

As mentioned above, prostaglandin is a pro-inflammatory mediator that causes painful sensations by binding to sensory endings and promotes tooth movement by stimulating bone remodelling. ${ }^{122-123} \mathrm{It}$ has been well documented that the synthesis of prostaglandin is mediated by COX enzymes and that NSAIDs inhibit the activity of COX enzymes. ${ }^{124}$ Therefore, NSAIDs could relieve orthodontic pain by inhibiting the release of prostaglandin. Because prostaglandin promotes local inflammation and bone remodelling, decreased levels of prostaglandin following NSAID intake could inhibit osteoclasts and reduce the rate of tooth movement. ${ }^{118}$ Moreover, a second mechanism by which NSAIDs impede orthodontic tooth movement has been proposed in which NSAIDs interfere with collagenase activity and procollagen synthesis, which results in impeded periodontal remodelling. ${ }^{125}$ Various types of NASIDs are now available for orthodontic patients, for example, acetaminophen, ibuprofen and celecoxib. Their individual superiority in pain control and efficacy in avoiding impeding tooth movement vary among different studies. ${ }^{122,126-128}$ However, regardless of each NSAID's superiority, it has been verified that almost all NSAIDs are effective in alleviating orthodontic pain, but their effects on the rate of tooth movement need to be validated in further studies.

\section{Mechanical approach}

Mechanical approaches have been proposed to relieve orthodontic pain, including vibration, chewing gums, biting wafers and acupuncture. ${ }^{129-133}$ Vibration is applied to patients' teeth through a vibrating device that is placed in their mouths. Patients are instructed to chew gum and bite wafers to alleviate orthodontic pain. Moreover, acupuncture is performed through inserting systemic needles at Hegu (LI4), which is located at the dorsum of the hand between the first and second metacarpal bones. ${ }^{130,134}$ The proposed mechanism for vibration, chewing gum and biting wafers lies in the fact that mechanical stimuli activate mechanoreceptors that transmit tactile signals while suppressing the transmission of painful signals. ${ }^{135}$ This process could explain the phenomenon that rubbing the skin of a painful site can relieve pain. In addition, as mentioned above, orthodontic forces squeeze periodontal vascular vessels and cause local ischaemia and subsequent local inflammation. Vibrations restore normal circulation and thus reduce pain. ${ }^{129}$ However, controversy exists for the effectiveness of vibration in relieving orthodontic pain. ${ }^{116-117,129,136}$ Due to scarce evidence, the effectiveness of chewing gum and biting wafers needs to be verified. Although acupuncture has been revealed to be effective for orthodontic pain relief, ${ }^{130,134}$ the mechanisms by which acupuncture relieves orthodontic pain remain largely unknown. ${ }^{137}$ Therefore, the effectiveness of the mechanical approach in relieving orthodontic pain necessitates further validation.

\section{Low-level laser therapy}

Low-level laser therapy has been extensively applied for pain relief in both medical and dental practice. ${ }^{138-139}$ Its applications has also been extended for the relief of orthodontic pain. ${ }^{140}$ Low-level laser therapy is accomplished through applying laser irradiation to the whole dental arch. A large body of evidence has confirmed the effectiveness of lowlevel laser therapy in alleviating orthodontic pain. ${ }^{141-143}$ However, its effectiveness has been refuted in several other studies. ${ }^{144-145}$ Moreover, several systematic reviews and meta-analyses have produced controversial results. ${ }^{146-148}$ These inconsistencies may be attributed to different irradiation durations and dosages. Thus, irradiation protocols need clarification, and their effectiveness necessitates further verification.

\section{Behavioural approach}

Behavioural approaches that are applied to relieve orthodontic pain include CBT, ${ }^{81}$ physical activity ${ }^{82}$ and music therapy. ${ }^{112}$ These behavioural modalities share a common feature: reassurance and attention distraction. It has been well documented that orthodontic patients feel anxiety and stress following orthodontic pain, and an immediate follow-up could significantly reduce their orthodontic pain levels, ${ }^{83-85}$ justifying that reassuring orthodontic patients may be a viable approach for controlling orthodontic pain. CBT, a form of psychotherapy, uses several treatment sessions to correct patients' negative altitudes and decrease their anxiety. As mentioned above, elevated anxiety increases patients' pain sensations through limbicsystem-mediated neural pathways. CBT, through reducing patients' anxiety, has been revealed to be effective in relieving orthodontic pain 
in clinical practice. ${ }^{14,81}$ Furthermore, music therapy and physical activity, through distracting patients' attention via the insular cortexmediated neural pathways, have been revealed to alleviate orthodontic pain in clinical practice. ${ }^{82,112}$ However, due to scarce evidence, the efficacy of behavioural therapy in orthodontic pain relief should be further confirmed.

\section{Gene therapy}

Gene therapy is defined as a method that delivers genes or DNA sequences to target cells that can transiently or stably express those genes or DNA sequences to alter the biological functions of those cells. Pain relief could be achieved through delivering endogenous opioid genes into neurons. ${ }^{149}$ Gene therapy for the alleviation of cancer pain has been applied in a clinical trial of humans, and acceptable outcomes were achieved. ${ }^{150}$ Different types of viral vectors have been developed for transducing genes of interest into target cells, including adenovirus, ${ }^{151}$ lentivirus, ${ }^{152}$ herpes simplex virus ${ }^{153}$ and adenoassociated virus. ${ }^{154}$ In particular, herpes simplex virus, by virtue of its neurotropism, is advantageous in gene therapy for neural disorders, including pain. ${ }^{155}$ It has been reported that gene therapy could be effective in alleviating trigeminal pain in rats through delivering an opioid gene into the trigeminal ganglia via herpes simplex virus. ${ }^{149}$ Similarly, herpes simplex virus can be used to deliver endogenous opioid genes or RNA interference sequences against pro-inflammatory genes (for example, CGRP) into the trigeminal ganglia to relieve orthodontic pain. At present, the application of gene therapy in clinical practice is limited by its biosafety concerns. ${ }^{156}$ Nevertheless, its potential biosafety concerns may be addressed in the near future, and it may become a viable and mainstream treatment strategy for orthodontic pain relief.

\section{CONCLUSION}

Orthodontic pain, an inflammatory pain, shares many similar features with common inflammation, but it has specific hallmarks. The exact molecular mechanisms of the pathogenesis of orthodontic pain are still poorly understood. Although the sensory pathways have been well documented, its collateral pathways, including those related to emotion, memory and cognition, are largely unknown. Thus, further functional MRI studies are urgently needed for delving into their exact neural pathways. Although NSAIDs have been validated to be effective in relieving orthodontic pain, its effects on tooth movement have yet to be verified. The effectiveness of other modalities, that is, mechanical approaches, low-level laser therapy and behavioural approaches, needs further confirmation. Furthermore, gene therapy, a novel and viable modality, is promising in the treatment of orthodontic pain in the future.

\section{ACKNOWLEDGEMENTS}

This work was supported by the National Natural Science Foundation of China (81571004, 81500884 and 81400549) and by the Orthodontic National Key Clinical Specialty Construction Program of China, West China Hospital of Stomatology, Sichuan University.

1 Asiry MA, Albarakati SF, Al-Marwan MS et al. Perception of pain and discomfort from elastomeric separators in Saudi adolescents. Saudi Med J 2014; 35(5): 504-507.

2 Kavaliauskiene A, Smailiene D, Buskiene I et al. Pain and discomfort perception among patients undergoing orthodontic treatment: results from one month followup study. Stomatologija 2012; 14(4): 118-125.
3 Rennick LA, Campbell PM, Naidu A et al. Effectiveness of a novel topical powder on the treatment of traumatic oral ulcers in orthodontic patients: a randomized controlled trial. Angle Orthod 2016; 86(3): 351-357.

4 Rakhshan H, Rakhshan V. Pain and discomfort perceived during the initial stage of active fixed orthodontic treatment. Saudi Dent J 2015; 27(2): 81-87.

5 Long $\mathrm{H}$, Zhou $\mathrm{Y}$, Pyakurel $\mathrm{U}$ et al. Comparison of adverse effects between lingual and labial orthodontic treatment. Angle Orthod 2013; 83(6): 1066-1073.

6 Krishnan V. Orthodontic pain: from causes to management-a review. Eur J Orthod 2007: 29(2): 170-179.

7 Panda S, Verma V, Sachan A et al. Perception of pain due to various orthodontic procedures. Quintessence Int 2015; 46(7): 603-609.

8 Baldini A, Nota A, Santariello C et al. Influence of activation protocol on perceived pain during rapid maxillary expansion. Angle Orthod 2015; 85(6): 1015-1020.

9 Mangnall LA, Dietrich T, Scholey JM. A randomized controlled trial to assess the pain associated with the debond of orthodontic fixed appliances. J Orthod 2013; 40(3): 188-196.

10 Tuncer Z, Ozsoy FS, Polat-Ozsoy O. Self-reported pain associated with the use of intermaxillary elastics compared to pain experienced after initial archwire placement. Angle Orthod 2011; 81(5): 807-811.

11 Normando TS, Calçada FS, Ursi WJ et al. Patients' report of discomfort and pain during debonding of orthodontic brackets: a comparative study of two methods. World J Orthod 2010; 11(4): e29-e34.

12 Marković E, Fercec J, Šćepan I et al. The correlation between pain perception among patients with six different orthodontic archwires and the degree of dental crowding. Srp Arh Celok Lek 2015; 143(3/4): 134-140.

13 Erdinç AM, Dinçer B. Perception of pain during orthodontic treatment with fixed appliances. Eur J Orthod 2004; 26(1): 79-85.

14 Wang J, Jian F, Chen J et al. Cognitive behavioral therapy for orthodontic pain control: a randomized trial. J Dent Res 2012; 91(6): 580-585.

15 Bergius $M$, Berggren $U$, Kiliaridis S. Experience of pain during an orthodontic procedure. Eur J Oral Sci 2002; 110(2): 92-98.

16 Johal A, Fleming PS, Al Jawad FA. A prospective longitudinal controlled assessment of pain experience and oral health-related quality of life in adolescents undergoing fixed appliance treatment. Orthod Craniofac Res 2014; 17(3): 178-186.

17 Yozgatian $\mathrm{JH}$, Zeredo JL, Hotokezaka $\mathrm{H}$ et al. Emotional stress- and pain-related behaviors evoked by experimental tooth movement. Angle Orthod 2008; 78(3): 487-494.

18 Li HS, Ke J, Zhao GZ et al. Effects of Danggui-Shaoyao-San on the influence of spatial learning and memory induced by experimental tooth movement. Chin Med J 2015; 128(14): 1948-1955.

19 Levrini L, Sacerdote $P$, Moretti $S$ et al. Changes of substance $P$ in the crevicular fluid in relation to orthodontic movement preliminary investigation. ScientificWorldJournal 2013; 2013: 896874.

20 Yamaguchi M, Takizawa T, Nakajima R et al. The Damon system and release of substance $\mathrm{P}$ in gingival crevicular fluid during orthodontic tooth movement in adults. World J Orthod 2009; 10(2): 141-146.

21 Chavarría-Bolaños D, Martinez-Zumaran A, Lombana $N$ et al. Expression of substance $P$, calcitonin gene-related peptide, $\beta$-endorphin and methionine-enkephalin in human dental pulp tissue after orthodontic intrusion: a pilot study. Angle Orthod 2014; 84(3): 521-526.

22 Sacerdote $\mathrm{P}$, Levrini L. Peripheral mechanisms of dental pain: the role of substance $\mathrm{P}$. Mediators Inflamm 2012; 2012: 951920.

23 Nimeri G, Kau CH, Abou-Kheir NS et al. Acceleration of tooth movement during orthodontic treatment-a frontier in orthodontics. Prog Orthod 2013; 14: 42.

24 Wang $\mathrm{H}$, Kohno $\mathrm{T}$, Amaya $\mathrm{F}$ et al. Bradykinin produces pain hypersensitivity by potentiating spinal cord glutamatergic synaptic transmission. J Neurosci 2005; 25(35): 7986-7992.

25 Schwarz AM. Tissue changes incident to orthodontic tooth movement. Int J Orthod 1932; 18(4): 331-352.

26 Noda K, Nakamura Y, Kogure K et al. Morphological changes in the rat periodontal ligament and its vascularity after experimental tooth movement using superelastic forces. Eur J Orthod 2009; 31(1): 37-45.

27 Rahman F, Harada F, Saito I et al. Detection of acid-sensing ion channel 3 (ASIC3) in periodontal Ruffini endings of mouse incisors. Neurosci Lett 2011; 488(2): 173-177.

28 Gao M, Long $\mathrm{H}$, Ma W et al. The role of periodontal ASIC3 in orofacial pain induced by experimental tooth movement in rats. Eur J Orthod 2015; doi:cjv082. [Epub ahead of print].

29 Qiao H, Zhou H, Zhu YJ et al. [The change of calcitonin gene- related peptide in periodontal tissue during orthodontic tooth movement]. Shanghai Kou Qiang Yi Xue 2012; 21(6): 606-611. Chinese.

30 Long H, Liao L, Gao M et al. Periodontal CGRP contributes to orofacial pain following experimental tooth movement in rats. Neuropeptides 2015; 52: 31-37.

31 de Hoon JN, Pickkers $\mathrm{P}$, Smits $\mathrm{P}$ et al. Calcitonin gene-related peptide: exploring its vasodilating mechanism of action in humans. Clin Pharmacol Ther 2003; 73(4): 312-321.

32 Kojima T, Yamaguchi M, Kasai K. Substance P stimulates release of RANKL via COX-2 expression in human dental pulp cells. Inflamm Res 2006; 55(2): 78-84.

33 Ren Y, Vissink A. Cytokines in crevicular fluid and orthodontic tooth movement. Eur J Oral Sci 2008; 116(2): 89-97.

34 Omori Y, Takahashi SS, Todoki K. Role of nitric oxide in post-ischemic gingival hyperemia in anesthetized dogs. Redox Rep 2002; 7(5): 300-303. 
35 D'Attillio M, Di Maio F, D'Arcangela C et al. Gingival endothelial and inducible nitric oxide synthase levels during orthodontic treatment: a cross-sectional study. Angle Orthod 2004; 74(6): 851-858.

36 Zeng $\mathrm{M}$, Kou X, Yang $\mathrm{R}$ et al. Orthodontic force induces systemic inflammatory monocyte responses. J Dent Res 2015; 94(9): 1295-1302.

37 He D, Kou X, Yang R et al. M1-like macrophage polarization promotes orthodontic tooth movement. J Dent Res 2015; 94(9): 1286-1294.

38 Scott DA, Krauss J. Neutrophils in periodontal inflammation. Front Oral Biol 2012; 15: 56-83.

39 Yan Y, Liu F, Kou X et al. T cells are required for orthodontic tooth movement. J Dent Res 2015; 94(10): 1463-1470.

40 Yamasaki K, Shibasaki Y, Fukuhara T. Behavior of mast cells in periodontal ligament associated with experimental tooth movement in rats. J Dent Res 1982; 61(12): 1447-1450.

41 Gameiro GH, Schultz C, Trein MP et al. Association among pain, masticatory performance, and proinflammatory cytokines in crevicular fluid during orthodontic treatment. Am J Orthod Dentofacial Orthop 2015; 148(6): 967-973.

42 De Filippo K, Dudeck A, Hasenberg M et al. Mast cell and macrophage chemokines CXCL1/CXCL2 control the early stage of neutrophil recruitment during tissue inflammation. Blood 2013; 121(24): 4930-4937.

43 Torres R, de Castellarnau C, Ferrer LL et al. Mast cells induce upregulation of P-selectin and intercellular adhesion molecule 1 on carotid endothelial cells in a new in vitro model of mast cell to endothelial cell communication. Immunol Cell Biol 2002; 80(2): 170-177

44 Zenobia C, Luo XL, Hashim A et al. Commensal bacteria-dependent select expression of CXCL2 contributes to periodontal tissue homeostasis. Cell Microbiol 2013; 15(8): 1419-1426.

45 Hajishengallis E, Hajishengallis G. Neutrophil homeostasis and periodontal health in children and adults. J Dent Res 2014; 93(3): 231-237.

46 Italiani P, Boraschi D. From Monocytes to M1/M2 macrophages: phenotypical vs. functional differentiation. Front Immunol 2014; 5: 514

47 Mills CD. M1 and M2 macrophages: oracles of health and disease. Crit Rev Immunol 2012; 32(6): 463-488.

48 Martinez FO, Gordon S. The M1 and M2 paradigm of macrophage activation: time for reassessment. F1000Prime Rep 2014; 6: 13

49 Luppanapornlarp S, Kajii TS, Surarit R et al. Interleukin-1 $\beta$ levels, pain intensity, and tooth movement using two different magnitudes of continuous orthodontic force. Eur $J$ Orthod 2010; 32(5): 596-601.

50 Giannopoulou C, Dudic A, Kiliaridis S. Pain discomfort and crevicular fluid changes induced by orthodontic elastic separators in children. J Pain 2006; 7(5): 367-376.

51 d'Apuzzo F, Cappabianca S, Ciavarella D et al. Biomarkers of periodontal tissue remodeling during orthodontic tooth movement in mice and men: overview and clinical relevance. Sci World J 2013; 2013: 105873.

52 Patil AK, Shetty AS, Setty S et al. Understanding the advances in biology of orthodontic tooth movement for improved ortho-perio interdisciplinary approach. J Indian Soc Periodontol 2013; 17(3): 309-318.

53 Hienz SA, Paliwal S, Ivanovski S. Mechanisms of bone resorption in periodontitis. $\mathrm{J}$ Immunol Res 2015; 2015: 615486.

54 Graves DT, Li J, Cochran DL. Inflammation and uncoupling as mechanisms of periodontal bone loss. J Dent Res 2011; 90(2): 143-153.

55 Mermut S, Bengi AO, Akin E et al. Effects of interferon-gamma on bone remodeling during experimental tooth movement. Angle Orthod 2007; 77(1): 135-141.

56 Liao L, Hua X, Long $\mathrm{H}$ et al. Expression patterns of nociceptin in rats following experimental tooth movement. Angle Orthod 2013; 83(6): 1022-1026.

57 Crossman AR, Neary D. Cranial nerves and cranial nerve nuclei// Crossman AR, Neary D eds. Neuroanatomy: an illustrated colour text. 5th edn. Philadelphia: Elsevier Health Sciences, 2015: 102-116.

58 Rahu MA, Grap MJ, Cohn JF et al. Facial expression as an indicator of pain in critically ill intubated adults during endotracheal suctioning. Am J Crit Care 2013; 22(5): 412-422.

59 Schmidt KL, Cohn JF. Human facial expressions as adaptations: evolutionary questions in facial expression research. Am J Phys Anthropol 2001; 33(Suppl): 3-24.

60 Liao L, Long $\mathrm{H}$, Zhang $\mathrm{L}$ et al. Evaluation of pain in rats through facial expression following experimental tooth movement. Eur J Oral Sci 2014; 122(2): 121-124.

61 Yang Z, Wang Y, Luo W et al. Trigeminal expression of N-methyl-D-aspartate receptor subunit 1 and behavior responses to experimental tooth movement in rats. Angle Orthod 2009; 79(5): 951-957.

62 Yang Z, Cao Y, Wang Y et al. Behavioural responses and expression of P2X3 receptor in trigeminal ganglion after experimental tooth movement in rats. Arch Oral Biol 2009; 54(1): 63-70.

63 Yang Z, Luo W, Wang J et al. Chemokine ligand 2 in the trigeminal ganglion regulates pain induced by experimental tooth movement. Angle Orthod 2014; 84(4): 730-736.

64 Zhang CD, Teng R, Lu Z et al. [Expression of TRPV1 and CGRP in rat trigeminal ganglion during orthodontic tooth movement.] Shanghai Kou Qiang Yi Xue 2015; 24(1): 6-12. Chinese.

65 Meng J, Ovsepian SV, Wang J et al. Activation of TRPV1 mediates calcitonin generelated peptide release, which excites trigeminal sensory neurons and is attenuated by a retargeted botulinum toxin with anti-nociceptive potential. J Neurosci 2009; 29(15): 4981-4992.
66 Sood M, Bhatt P, Sessle BJ. Mechanical and thermal hypersensitivities associated with orthodontic tooth movement: a behavioral rat model for orthodontic tooth movement-induced pain. J Oral Facial Pain Headache 2015; 29(1): 60-69.

67 Leavitt AH, King GJ, Ramsay DS et al. A longitudinal evaluation of pulpal pain during orthodontic tooth movement. Orthod Craniofac Res 2002; 5(1): 29-37.

68 Costa FA, Moreira Neto FL. [Satellite glial cells in sensory ganglia: its role in pain.] Rev Bras Anestesiol 2015; 65(1): 73-81. Portuguese.

69 Feldman-Goriachnik R, Hanani M. Functional study of endothelin B receptors in satellite glial cells in trigeminal ganglia. Neuroreport 2011; 22(10): 465-469.

70 Kushnir R, Cherkas PS, Hanani M. Peripheral inflammation upregulates P2X receptor expression in satellite glial cells of mouse trigeminal ganglia: a calcium imaging study. Neuropharmacology 2011; 61(4): 739-746.

71 Vause CV, Durham PL. CGRP stimulation of iNOS and NO release from trigeminal ganglion glial cells involves mitogen-activated protein kinase pathways. J Neurochem 2009; 110(3): 811-821.

72 Li J, Vause CV, Durham PL. Calcitonin gene-related peptide stimulation of nitric oxide synthesis and release from trigeminal ganglion glial cells. Brain Res 2008; 1196: 22-32.

73 Bellamy J, Bowen EJ, Russo AF et al. Nitric oxide regulation of calcitonin gene-related peptide gene expression in rat trigeminal ganglia neurons. Eur J Neurosci 2006; 23(8): 2057-2066.

74 Nieuwenhuys R. The insular cortex: a review. Prog Brain Res 2012; 195: 123163.

75 Starr CJ, Sawaki L, Wittenberg GF et al. Roles of the insular cortex in the modulation of pain: insights from brain lesions. J Neurosci 2009; 29(9): 2684-2694.

76 Sandhu SS, Sandhu J. Orthodontic pain: an interaction between age and sex in early and middle adolescence. Ang/e Orthod 2013; 83(6): 966-972.

77 Campos MJ, Fraga MR, Raposo NR et al. Assessment of pain experience in adults and children after bracket bonding and initial archwire insertion. Dental Press J Orthod 2013; 18(5): 32-37.

78 Yang X, Sun J, Chen T et al. Amplitude of low-frequency fluctuation of BOLD signal and resting-state functional connectivity analysis of brains in patients with orthodontic pain. J Med Imag Health Inform 2015; 5(7): 1548-1552.

79 Bantick SJ, Wise RG, Ploghaus A et al. Imaging how attention modulates pain in humans using functional MRI. Brain 2002; 125(Pt 2): 310-319.

80 Atlas LY, Wager TD. A meta-analysis of brain mechanisms of placebo analgesia: consistent findings and unanswered questions. Handb Exp Pharmacol 2014; 225: 37-69.

81 Wang J, Wu D, Shen $Y$ et al. Cognitive behavioral therapy eases orthodontic pain: EEG states and functional connectivity analysis. Oral Dis 2015; 21(5): 572-582.

82 Sandhu SS, Sandhu J. Effect of physical activity level on orthodontic pain perception and analgesic consumption in adolescents. Am J Orthod Dentofacial Orthop 2015; 148(4): 618-627.

83 Cozzani M, Ragazzini G, Delucchi A et al. Self-reported pain after orthodontic treatments: a randomized controlled study on the effects of two follow-up procedures. Eur J Orthod 2016; 38 (3):266-271.

84 Keith DJ, Rinchuse DJ, Kennedy $M$ et al. Effect of text message follow-up on patient's self-reported level of pain and anxiety. Angle Orthod 2013; 83(4): 605-610.

85 Bartlett BW, Firestone AR, Vig KW et al. The influence of a structured telephone call on orthodontic pain and anxiety. Am J Orthod Dentofacial Orthop 2005; 128(4): 435-441.

86 Wang J, Tang $X$, Shen $Y$ et al. The correlations between health-related quality of life changes and pain and anxiety in orthodontic patients in the initial stage of treatment. Biomed Res Int 2015; 2015: 725913.

87 Beck VJ, Farella M, Chandler NP et al. Factors associated with pain induced by orthodontic separators. J Oral Rehabil 2014; 41(4): 282-288.

88 Bergius M, Broberg AG, Hakeberg M et al. Prediction of prolonged pain experiences during orthodontic treatment. Am J Orthod Dentofacial Orthop 2008; 133(3): 339.e1-339.e8.

89 Rajmohan V, Mohandas E. The limbic system. Indian J Psychiatry 2007; 49(2): 132-139.

90 Novaes AP, da Rocha MJ, Leite-Panissi CR. Tooth movement activates the central amygdala and the lateral hypothalamus by the magnitude of the force applied. Angle Orthod 2010; 80(1): 111-115.

91 Ossipov MH, Dussor GO, Porreca F. Central modulation of pain. J Clin Invest 2010; 120(11): 3779-3787.

92 Heredia-Rizo AM, Oliva-Pascual-Vaca A, Rodríguez-Blanco C et al. Craniocervical posture and trigeminal nerve mechanosensitivity in subjects with a history of orthodontic use: a cross-sectional study. Cranio 2013; 31(4): 252-259.

93 Phelps EA. Human emotion and memory: interactions of the amygdala and hippocampal complex. Curr Opin Neurobiol 2004; 14(2): 198-202.

94 Ding TT, Xu XX, Cao $Y$ et al. Inflammatory pain memory facilitates occlusal interference-induced masticatory muscle hyperalgesia in rats. Eur J Pain 2016; 20(3): 353-364.

95 Gondo M, Moriguchi Y, Kodama N et al. Daily physical complaints and hippocampal function: an fMRI study of pain modulation by anxiety. Neuroimage 2012; 63(3): 1011-1019.

96 Ploghaus A, Narain C, Beckmann CF et al. Exacerbation of pain by anxiety is associated with activity in a hippocampal network. J Neurosci 2001; 21(24): 9896-9903.

97 Raoof M, Esmaeili-Mahani S, Nourzadeh M et al. Noxious stimulation of the rat tooth pulp may impair learning and memory through the induction of hippocampal apoptosis. J Oral Facial Pain Headache 2015; 29(4): 390-397. 
98 Forkmann K, Wiech K, Ritter C et al. Pain-specific modulation of hippocampal activity and functional connectivity during visual encoding. J Neurosci 2013; 33(6): 2571-2581.

99 Shibazaki T, Yozgatian JH, Zeredo JL et al. Effect of celecoxib on emotional stress and pain-related behaviors evoked by experimental tooth movement in the rat. Angle Orthod 2009; 79(6): 1169-1174.

100 Magdalena CM, Navarro VP, Park DM et al. C-fos expression in rat brain nucle following incisor tooth movement. J Dent Res 2004; 83(1): 50-54.

101 Samuels ER, Szabadi E. Functional neuroanatomy of the noradrenergic locus coeruleus: its roles in the regulation of arousal and autonomic function part I: principles of functional organisation. Curr Neuropharmacol 2008; 6(3): 235253

102 Malick A, Strassman RM, Burstein R. Trigeminohypothalamic and reticulohypothalamic tract neurons in the upper cervical spinal cord and caudal medulla of the rat. J Neurophysiol 2000; 84(4): 2078-2112.

103 Sara SJ, Bouret S. Orienting and reorienting: the locus coeruleus mediates cognition through arousal. Neuron 2012; 76(1): 130-141.

104 Lesniak A, Lipkowski AW. Opioid peptides in peripheral pain control. Acta Neurobiol Exp (Wars) 2011; 71(1): 129-138.

105 Balam TA, Yamashiro T, Zheng $L$ et al. Experimental tooth movement upregulates preproenkephalin mRNA in the rat trigeminal nucleus caudalis and oralis. Brain Res 2005; 1036(1/2): 196-201.

106 Behbehani MM. Functional characteristics of the midbrain periaqueductal gray. Prog Neurobiol 1995; 46(6): 575-605.

107 Benarroch EE. Periaqueductal gray: an interface for behavioral control. Neurology 2012; 78(3): 210-217.

108 Wang QP, Nakai Y. The dorsal raphe: an important nucleus in pain modulation. Brain Res Bull 1994; 34(6): 575-585.

109 Sasa M, Munekiyo K, Takaori S. Dorsal raphe stimulation produces inhibitory effect on trigeminal nucleus neurons. Brain Res 1976; 101(2): 199-207.

$110 \mathrm{Li}$ YQ, Takada M, Matsuzaki S et al. Identification of periaqueductal gray and dorsal raphe nucleus neurons projecting to both the trigeminal sensory complex and forebrain structures: a fluorescent retrograde double-labeling study in the rat. Brain Res 1993; 623(2): 267-277.

111 Dobek CE, Beynon ME, Bosma RL et al. Music modulation of pain perception and pain-related activity in the brain, brain stem, and spinal cord: a functional magnetic resonance imaging study. J Pain 2014; 15(10): 1057-1068.

$112 \mathrm{Xu} \mathrm{X}$, Zhang $\mathrm{L}$, Jiang $\mathrm{Y}$ et al. [Clinical research of music in relieving orthodontic pain.] Hua Xi Kou Qiang Yi Xue Za Zhi 2013; 31(4): 365-368. Chinese.

113 Gupta M, Kandula S, Laxmikanth SM et al. Controlling pain during orthodontic fixed appliance therapy with non-steroidal anti-inflammatory drugs (NSAID): a randomized, double-blinded, placebo-controlled study. J Orofac Orthop 2014; 75(6): 471-476.

114 Angelopoulou MV, Vlachou V, Halazonetis DJ. Pharmacological management of pain during orthodontic treatment: a meta-analysis. Orthod Craniofac Res 2012; 15(2) 71-83.

115 Xiaoting L, Yin T, Yangxi C. Interventions for pain during fixed orthodontic appliance therapy. A systematic review. Angle Orthod 2010; 80(5): 925-932.

116 Woodhouse NR, DiBiase AT, Papageorgiou SN et al. Supplemental vibrational force does not reduce pain experience during initial alignment with fixed orthodontic appliances: a multicenter randomized clinical trial. Sci Rep 2015; 5: 17224

117 Miles P, Smith H, Weyant R et al. The effects of a vibrational appliance on tooth movement and patient discomfort: a prospective randomised clinical trial. Aust Orthod J 2012; 28(2): 213-218.

118 Arias OR, Marquez-Orozco MC. Aspirin, acetaminophen, and ibuprofen: their effects on orthodontic tooth movement. Am J Orthod Dentofacial Orthop 2006; 130(3): 364-370.

119 Arantes GM, Arantes VM, Ashmawi HA et al. Tenoxicam controls pain without altering orthodontic movement of maxillary canines. Orthod Craniofac Res 2009; 12(1): 14-19.

120 Krasny M, Zadurska M, Cessak G et al. Analysis of effect of non-steroidal antiinflammatory drugs on teeth and oral tissues during orthodontic treatment. Report based on literature review. Acta Pol Pharm 2013; 70(3): 573-577.

121 Ashkenazi M, Levin L. Pain prevention and management during orthodontic treatment as perceived by patients. Orthodontics : Chic 2012; 13(1): e76-e81.

122 Karthi M, Anbuslevan GJ, Senthilkumar KP et al. NSAIDs in orthodontic tooth movement. J Pharm Bioallied Sci 2012; 4(Suppl 2): S304-S306.

123 Yamasaki K, Miura F, Suda T. Prostaglandin as a mediator of bone resorption induced by experimental tooth movement in rats. J Dent Res 1980; 59(10): 1635-1642

124 Shenoy N, Shetty S, Ahmed J et al. The pain management in orthodontics. J Clin Diagn Res 2013; 7(6): 1258-1260.

125 Kyrkanides S, O'Banion MK, Subtelny JD. Nonsteroidal anti-inflammatory drugs in orthodontic tooth movement: metalloproteinase activity and collagen synthesis by endothelial cells. Am J Orthod Dentofacial Orthop 2000; 118(2): 203-209.

126 Shetty N, Patil AK, Ganeshkar SV et al. Comparison of the effects of ibuprofen and acetaminophen on PGE2 levels in the GCF during orthodontic tooth movement: a human study. Prog Orthod 2013; 14: 6

127 Patel S, McGorray SP, Yezierski R et al. Effects of analgesics on orthodontic pain Am J Orthod Dentofacial Orthop 2011; 139(1): e53-e58.

128 de Carlos F, Cobo J, Perillan C et al. Orthodontic tooth movement after different coxib therapies. Eur J Orthod 2007; 29(6): 596-599.
129 Lobre WD, Callegari BJ, Gardner G et al. Pain control in orthodontics using a micropulse vibration device: A randomized clinical trial. Angle Orthod 2015. [Epub ahead of print].

130 Boleta-Ceranto Dde C, de Souza RS, Silverio-Lopes S et al. Orthodontic post-adjustment pain control with acupuncture. Dental Press J Orthod 2014; 19(4): 100-106.

131 Farzanegan $\mathrm{F}$, Zebarjad SM, Alizadeh $\mathrm{S}$ et al. Pain reduction after initial archwire placement in orthodontic patients: a randomized clinical trial. Am J Orthod Dentofacial Orthop 2012; 141(2): 169-173.

132 Benson PE, Razi RM, Al-Bloushi RJ. The effect of chewing gum on the impact, pain and breakages associated with fixed orthodontic appliances: a randomized clinical trial. Orthod Craniofac Res 2012; 15(3): 178-187.

133 Murdock S, Phillips C, Khondker Z et al. Treatment of pain after initial archwire placement: a noninferiority randomized clinical trial comparing over-the-counter analgesics and bite-wafer use. Am J Orthod Dentofacial Orthop 2010; 137(3): 316-323.

134 Vachiramon A, Wang WC. Acupuncture and acupressure techniques for reducing orthodontic post-adjustment pain. J Contemp Dent Pract 2005; 6(1): 163-167.

135 Guyton AC, Hall JE. Somatic sensations: II pain, headache, and thermal sensations// Textbook of medical physiology. 10th edn. Singapore: Health Sciences Asia, Elsevier Sciences, 2000: 552-563.

136 Marie SS, Powers M, Sheridan JJ. Vibratory stimulation as a method of reducing pain after orthodontic appliance adjustment. J Clin Orthod 2003; 37(4): 205-208.

137 Yang ZL, Ouyang Z, Cheng YG et al. A neuromagnetic study of acupuncturing LI-4 (Hegu). Acupunct Electrother Res 1995; 20(1): 15-20.

138 Huang Z, Ma J, Chen J et al. The effectiveness of low-level laser therapy for nonspecific chronic low back pain: a systematic review and meta-analysis. Arthritis Res Ther 2015; 17: 360.

139 Landucci A, Wosny AC, Uetanabaro LC et al. Efficacy of a single dose of low-level laser therapy in reducing pain, swelling, and trismus following third molar extraction surgery. Int J Oral Maxillofac Surg 2016; 45(3): 392-398.

140 Stein S, Korbmacher-Steiner H, Popovic N et al. Pain reduced by low-level laser therapy during use of orthodontic separators in early mixed dentition. J Orofac Orthop 2015; 76(5): 431-439

141 Artés-Ribas M, Arnabat-Dominguez J, Puigdollers A. Analgesic effect of a low-level laser therapy $(830 \mathrm{~nm})$ in early orthodontic treatment. Lasers Med Sci 2013; 28(1): 335-341.

142 Eslamian L, Borzabadi-Farahani A, Hassanzadeh-Azhiri A et al. The effect of 810-nm low-level laser therapy on pain caused by orthodontic elastomeric separators. Lasers Med Sci 2014; 29(2): 559-564.

143 Tortamano A, Lenzi DC, Haddad AC et al. Low-level laser therapy for pain caused by 27 placement of the first orthodontic archwire: a randomized clinical trial. Am J Orthod Dentofacial Orthop 2009; 136(5): 662-667.

144 Heravi F, Moradi A, Ahrari F. The effect of low level laser therapy on the rate of tooth movement and pain perception during canine retraction. Oral Health Dent Manag 2014; 13(2): 183-188

145 Dalaie K, Hamedi R, Kharazifard MJ et al. Effect of low-level laser therapy on orthodontic tooth movement: a clinical investigation. J Dent (Tehran) 2015; 12(4): 249-256.

146 Shi Q, Yang S, Jia $\mathrm{F}$ et al. Does low level laser therapy relieve the pain caused by the placement of the orthodontic separators? - A meta-analysis. Head Face Med 2015; 11: 28.

147 Li FJ, Zhang JY, Zeng XT et al. Low-level laser therapy for orthodontic pain: a systematic review. Lasers Med Sci 2015; 30(6): 1789-1803.

$148 \mathrm{He}$ WL, Li CJ, Liu ZP et al. Efficacy of low-level laser therapy in the management of orthodontic pain: a systematic review and meta-analysis. Lasers Med Sci 2013; 28(6): 1581-1589.

149 Tzabazis AZ, Klukinov M, Feliciano DP et al. Gene therapy for trigeminal pain in mice. Gene Ther 2014; 21(4): 422-426.

150 Fink DJ, Wechuck J, Mata $M$ et al. Gene therapy for pain: results of a phase clinical trial. Ann Neurol 2011; 70(2): 207-212.

151 Watanabe M, Nasu Y, Kumon H. Adenovirus-mediated REIC/Dkk-3 gene therapy: development of an autologous cancer vaccination therapy (Review). Oncol Lett 2014; 7(3): 595-601.

152 Seo JH, Jeong ES, Choi YK. Therapeutic effects of lentivirus-mediated shRNA targeting of cyclin D1 in human gastric cancer. BMC Cancer 2014; 14: 175.

153 Grinde B. Herpesviruses: latency and reactivation - viral strategies and host response. J Oral Microbiol 2013; 5: 22766

154 Fischer G, Pan B, Vilceanu D et al. Sustained relief of neuropathic pain by AAV targeted expression of CBD3 peptide in rat dorsal root ganglion. Gene Ther 2014; 21 (1): 44-51.

155 Smith G. Herpesvirus transport to the nervous system and back again. Annu Rev Microbiol 2012; 66: 153-176.

156 VandenDriessche T, Collen D, Chuah MK. Biosafety of onco-retroviral vectors. Curr Gene Ther 2003; 3(6): 501-515.

(C) $(\$)$ This work is licensed under a Creative Commons AttributionNonCommercial-NoDerivs 4.0 International License. The images or other third party material in this article are included in the article's Creative Commons license, unless indicated otherwise in the credit line; if the material is not included under the Creative Commons license, users will need to obtain permission from the license holder to reproduce the material. To view a copy of this license, visit http:// creativecommons.org/licenses/by-nc-nd/4.0/

(C) The Author(s) 2016 